\title{
An Experimental Comparison between Conventional and New Direct Torque Control Strategies of Induction Machine using DSPACE TMS 320F2812
}

\author{
Essaadi Mouna, \\ Khafallah Mohamed \\ Hassan II University-ENSEM \\ Casablanca, Morocco.
}

\author{
Chaikhy Hamid \\ Université Chouaib Doukkali- \\ ENSA \\ El Jadida, Morocco
}

\author{
El Afia Aziz \\ Université Hassan II-ENSAM, \\ Casablanca, Morocco.
}

\begin{abstract}
This paper presents an experimental comparison between six sectors direct torque control (6_DTC) and twelve sectors direct torque control (12_DTC).Those different strategies are implemented by using a DSPACE experimental configuration and compared in term of torque dynamic and current distortions.
\end{abstract}

\section{Keywords}

Six sectors DTC, Twelve sectors DTC, DSPACE experimental configuration, Torque dynamic, Stator current distortions.

\section{INTRODUCTION}

Traditionally, variable speed electric machines were based on DC motors, since the magnetic flux and torque are easily controlled by the stator and rotor current, respectively [1]. For the last two decades, DC motors was replaced by AC motors. Induction Machine (IM) is one of the most robust AC motors that have been widely used in industry. However, due to their highly coupled non-linear structure, a high performance control of IM is a challenging problem [2]. Field oriented control (FOC) has been till now employed in high performance industry applications using IM instead of DC motors. FOC of IM has achieved a quick torque response and has many similar advantages to DC motors. However, it depends to accurate parameter identification to achieve the expected performance [3][1]. During the last decade, a new control method called DTC has been created. DTC is characterized by his simple implementation and robustness. However, 6_DTC has some disadvantages compared with new DTC strategies, like a slow response in both starts up and changes in either flux or torque [4] also the distortions are one of their main drawbacks. Different solutions have been proposed to overcome the mentioned drawbacks, 12_DTC [4]. The aim of this paper is to validate the simulation results and give an experimental comparison between 6_DTC and 12_DTC using DSPACE experimental configuration, to figure out the advantages and disadvantages of each of them.

\section{PRINCIPLE OF 6_DTC}

Since M. Depenbrock and I. Takahashi proposed DTC for IM in the middle of 1980 's, more than decade has passed. It is getting more and more popular nowadays [5]. The instantaneous values of the stator flux and torque are calculated from stator variable by using a closed loop estimator [6]. As shown in Fig. 1, stator flux and torque can be controlled directly and independently by properly selecting the inverter switching configuration [4].

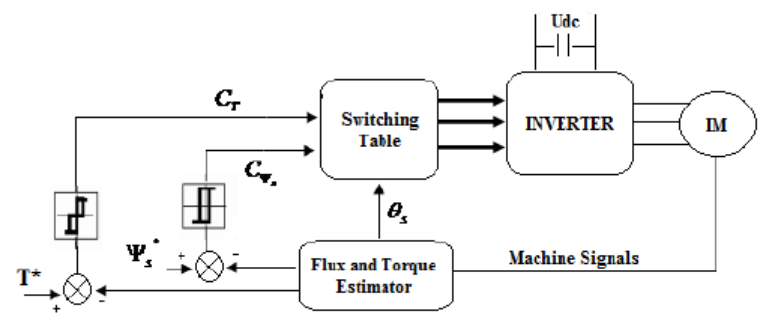

Fig 1: block diagram of the DTC control technique

By using an $\alpha-\beta$ stationary stator reference frame, the stator flux linkage $\psi_{\mathrm{s}}$ and electromagnetic torque are calculating by using:

$$
\psi_{\mathrm{s}}=\sqrt{{\psi_{\alpha \mathrm{s}}{ }^{2}+\psi_{\beta s}^{2}}^{2}}
$$

Where:

$$
\begin{gathered}
\psi_{\alpha s}=\int_{0}^{t}\left(V_{\alpha s}-R_{s} I_{\alpha s}\right) d t \\
\psi_{\beta s}=\int_{0}^{t}\left(V_{\beta s}-R_{s} I_{\beta s}\right) d t
\end{gathered}
$$

The angle $\theta_{\mathrm{s}}$ is equal to:

$$
\begin{aligned}
\theta_{\mathrm{s}}=\tan ^{-1}\left(\frac{\psi_{\beta s}}{\psi_{\alpha s}}\right) & \\
\mathrm{T} & =\mathrm{p}\left[\psi_{\alpha \mathrm{s}} \mathrm{I}_{\beta \mathrm{s}}-\psi_{\beta \mathrm{s}} \mathrm{I}_{\alpha \mathrm{s}}\right]
\end{aligned}
$$

The error between the estimated torque and the reference torque $\mathrm{T}^{*}$ is the input of a three level hysteresis comparator, whereas the error between the estimated stator flux magnitude $\psi_{\mathrm{s}}$ and he reference stator flux magnitude $\psi_{\mathrm{s}} *$ is the input of a two level hysteresis comparator.
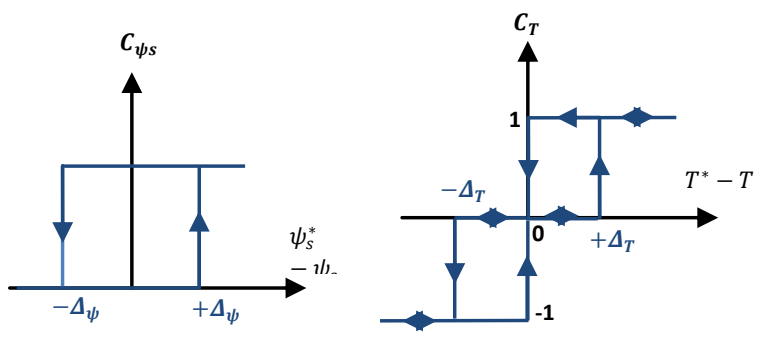

Fig 2: Torque hysteresis comparator. Fig 3 : Flux hysteresis comparator. 
Figs. 2 and 3 illustrate the torque and flux comparators, respectively.

The selection of the appropriate voltage vector is based on the switching table given in Tab. 1. The input quantities are the flux sector and the outputs of the two hysteresis comparators.

To determine stator vector voltage to be applied, First the circular trajectory of the stator flux is divided into six symmetrical sectors referred as the inverter voltage vectors [7]. Then, the effect of each stator voltage on the flux and torque is studied. When the stator flux is in sector $\mathrm{Si}$, vectors $V_{i+1}$ or $V_{i-1}$ are selected to increase its amplitude, and $V_{i+2}$ or $V_{i-2}$ to decrease it. However $V_{i+1}$ or $V_{i+2}$ increase the torque and $V_{i-1}$ or $V_{i-2}$ decrease it. Fig. 4 shows the effect of those different choices in sector $\mathrm{S} 1$.

Table 1. Basic Switching

\begin{tabular}{|c|c|c|c|c|c|c|c|}
\hline \multirow{2}{*}{\multicolumn{2}{|c|}{$\begin{array}{l}\text { Outputs of } \\
\text { hysteresis } \\
\text { comparators }\end{array}$}} & \multicolumn{6}{|c|}{ Sector } \\
\hline & & \multirow{2}{*}{1} & \multirow{2}{*}{2} & \multirow{2}{*}{3} & \multirow{2}{*}{4} & \multirow{2}{*}{5} & \multirow{2}{*}{6} \\
\hline$C_{\psi s}$ & $C_{T e}$ & & & & & & \\
\hline \multirow{3}{*}{1} & 1 & $\bar{V}_{2}$ & $\bar{V}_{3}$ & $\bar{V}_{4}$ & $\bar{V}_{5}$ & $\bar{V}_{6}$ & $\bar{V}_{1}$ \\
\hline & 0 & $\bar{V}_{7}$ & $\bar{V}_{0}$ & $\bar{V}_{7}$ & $\bar{V}_{0}$ & $\bar{V}_{7}$ & $\bar{V}_{0}$ \\
\hline & -1 & $\bar{V}_{6}$ & $\bar{V}_{1}$ & $\bar{V}_{2}$ & $\bar{V}_{3}$ & $\bar{V}_{4}$ & $\bar{V}_{5}$ \\
\hline \multirow{3}{*}{0} & 1 & $\bar{V}_{3}$ & $\bar{V}_{4}$ & $\bar{V}_{5}$ & $\bar{V}_{6}$ & $\bar{V}_{1}$ & $\bar{V}_{2}$ \\
\hline & 0 & $\bar{V}_{0}$ & $\bar{V}_{7}$ & $\bar{V}_{0}$ & $\bar{V}_{7}$ & $\bar{V}_{0}$ & $\overline{\bar{V}}_{7}$ \\
\hline & -1 & $\bar{V}_{5}$ & $\bar{V}_{6}$ & $\bar{V}_{1}$ & $\bar{V}_{2}$ & $\bar{V}_{3}$ & $\bar{V}_{4}$ \\
\hline
\end{tabular}

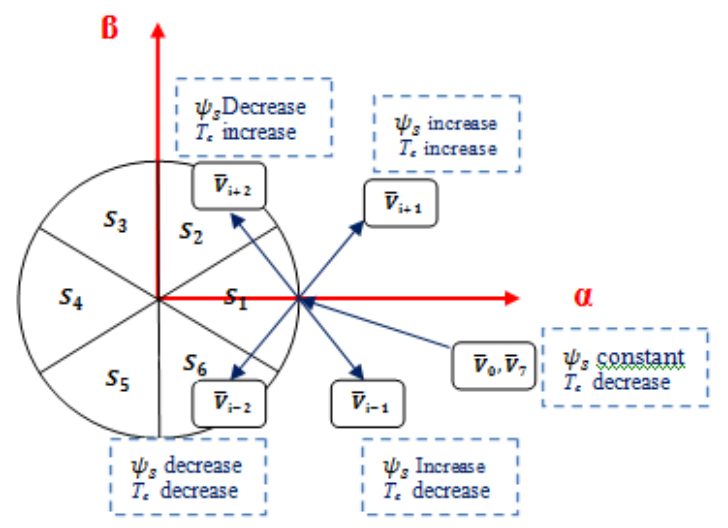

Fig 4: Effect of different Vs choices on the torque and stator flux in sector $\mathrm{S} 1$.

As shown in Tab.1, the two vectors $\overline{\mathbf{V}}_{\mathbf{1}}$ and $\overline{\mathbf{V}}_{\mathbf{4}}$ are not used in 6_DTC, because, they can increase or decrease the torque at the same sector depending on if the position is in its first 30 degrees or in its second ones. To eliminate this ambiguity in torque a new method is used "12_DTC".

\section{PRINCIPLE OF 12_DTC}

In C_DTC there are two states per sector $\mathrm{i}$ that present a torque ambiguity which are $\bar{V}_{i}$ and $\bar{V}_{i+1}$. Therefore, they are never used.

If the stator flux locus is divided into twelve sectors [8] instead of just six, all six active states will be used per sector and the problem of ambiguity of both flux and torque will be solved. This new stator flux locus is introduced in Fig.5.[9][10][11]

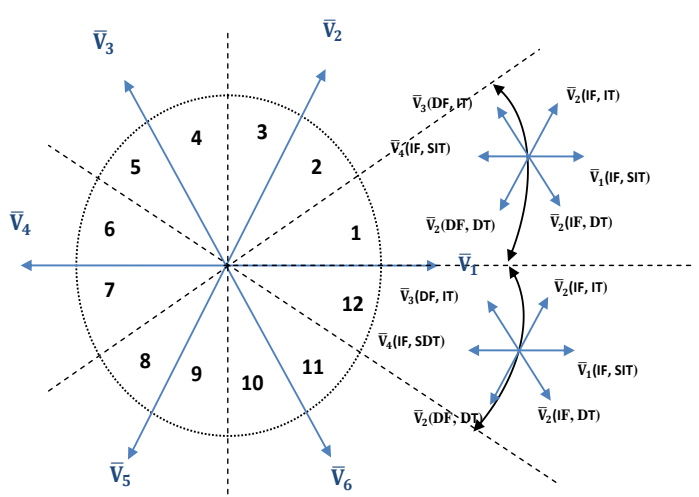

Fig 5: 12_DTC - Increase Torque/ Decrease torque/Increase flux/decrease Flux/Small increase of Torque/Small decrease of torque.

Table 2. The voltage vectors effect in first and twelfth sectors

\begin{tabular}{|c|c|c|c|c|c|c|c|c|c|c|c|c|c|}
\hline \multicolumn{14}{|c|}{ sectors } \\
\hline \multicolumn{2}{|c|}{ Sector } & \multirow{2}{*}{1} & \multirow{2}{*}{2} & \multirow{2}{*}{3} & \multirow{2}{*}{4} & \multirow{2}{*}{5} & \multirow{2}{*}{6} & \multirow{2}{*}{7} & \multirow{2}{*}{8} & \multirow{2}{*}{9} & \multirow{2}{*}{10} & & \\
\hline$C_{\psi s}$ & $C_{T e}$ & & & & & & & & & & & & \\
\hline \multirow{4}{*}{1} & 2 & $\overline{\mathrm{V}}_{2}$ & $\overline{\mathrm{V}}_{3}$ & $\overline{\mathrm{V}}_{3}$ & $\overline{\mathrm{V}}_{4}$ & $\overline{\mathrm{V}}_{4}$ & $\overline{\mathrm{V}}_{5}$ & $\bar{V}_{5}$ & $\overline{\mathrm{V}}_{6}$ & $\bar{V}_{6}$ & $\overline{\mathrm{V}}_{1}$ & $\overline{\mathrm{V}}_{1}$ & $\overline{\mathrm{V}}_{2}$ \\
\hline & 1 & $\overline{\mathrm{V}}_{2}$ & $\overline{\mathrm{V}}_{2}$ & $\overline{\mathrm{V}}_{3}$ & $\overline{\mathrm{V}}_{3}$ & $\overline{\mathrm{V}}_{4}$ & $\overline{\mathrm{V}}_{4}$ & $\overline{\mathrm{V}}_{5}$ & $\overline{\mathrm{V}}_{5}$ & $\overline{\mathrm{V}}_{6}$ & $\overline{\mathrm{V}}_{6}$ & $\bar{V}_{1}$ & $\overline{\mathrm{V}}_{1}$ \\
\hline & -1 & $\bar{V}_{1}$ & $\overline{\mathrm{V}}_{1}$ & $\overline{\mathrm{V}}_{2}$ & $\overline{\mathrm{V}}_{2}$ & $\bar{V}_{3}$ & $\overline{\mathrm{V}}_{3}$ & $\overline{\mathrm{V}}_{4}$ & $\overline{\mathrm{V}}_{4}$ & $\overline{\mathrm{V}}_{5}$ & $\overline{\mathrm{V}}_{5}$ & $\overline{\mathrm{V}}_{6}$ & $\overline{\mathrm{V}}_{6}$ \\
\hline & -2 & $\overline{\mathrm{V}}_{6}$ & $\overline{\mathrm{V}}_{1}$ & $\bar{V}_{1}$ & $\overline{\mathrm{V}}_{2}$ & $\overline{\mathrm{V}}_{2}$ & $\overline{\mathrm{V}}_{3}$ & $\overline{\mathrm{V}}_{3}$ & $\overline{\mathrm{V}}_{4}$ & $\overline{\mathrm{V}}_{4}$ & $\overline{\mathrm{V}}_{5}$ & $\overline{\mathrm{V}}_{5}$ & $\overline{\mathrm{V}}_{6}$ \\
\hline \multirow{4}{*}{0} & 2 & $\overline{\mathrm{V}}_{3}$ & $\overline{\mathrm{V}}_{4}$ & $\overline{\mathrm{V}}_{4}$ & $\bar{V}_{5}$ & $\overline{\mathrm{V}}_{5}$ & $\overline{\mathrm{V}}_{6}$ & $\overline{\mathrm{V}}_{6}$ & $\overline{\mathrm{V}}_{1}$ & $\bar{V}_{1}$ & $\overline{\mathrm{V}}_{2}$ & $\overline{\mathrm{V}}_{2}$ & $\overline{\mathrm{V}}_{3}$ \\
\hline & 1 & $\overline{\mathrm{V}}_{4}$ & $\overline{\mathrm{V}}_{4}$ & $\overline{\mathrm{V}}_{5}$ & $\overline{\mathrm{V}}_{5}$ & $\overline{\mathrm{V}}_{6}$ & $\overline{\mathrm{V}}_{6}$ & $\bar{V}_{1}$ & $\overline{\mathrm{V}}_{1}$ & $\overline{\mathrm{V}}_{2}$ & $\begin{array}{l}\overline{\mathrm{V}}_{2} \\
*\end{array}$ & $\overline{\mathrm{V}}_{3}$ & $\overline{\mathrm{V}}_{3}$ \\
\hline & -1 & $\overline{\mathrm{V}}_{7}$ & $\overline{\mathrm{V}}_{5}$ & $\overline{\mathrm{V}}_{0}$ & $\overline{\mathrm{V}}_{6}$ & $\overline{\mathrm{V}}_{7}$ & $\overline{\mathrm{V}}_{1}$ & $\overline{\mathrm{V}}_{0}$ & $\overline{\mathrm{V}}_{2}$ & $\overline{\mathrm{V}}_{7}$ & $\overline{\mathrm{V}}_{3}$ & $\overline{\mathrm{V}}_{0}$ & $\overline{\mathrm{V}}_{4}$ \\
\hline & -2 & $\bar{V}_{5}$ & $\overline{\mathrm{V}}_{6}$ & $\overline{\mathrm{V}}_{6}$ & $\overline{\mathrm{V}}_{1}$ & $\bar{V}_{1}$ & $\overline{\mathrm{V}}_{2}$ & $\overline{\mathrm{V}}_{2}$ & $\overline{\mathrm{V}}_{3}$ & $\overline{\mathrm{V}}_{3}$ & $\overline{\mathrm{V}}_{4}$ & $\overline{\mathrm{V}}_{4}$ & $\overline{\mathrm{V}}_{5}$ \\
\hline
\end{tabular}

It's clearly noticed in Tab. 2 that all the six vectors are used disappearing all ambiguities. 
TABLE 3. Switching table of the 12_DTC

\begin{tabular}{|c|c|c|c|}
\cline { 3 - 4 } \multicolumn{2}{c|}{} & Increasing & Decreasing \\
\hline \multirow{3}{*}{$s_{12}$} & Flux & $\overline{\mathrm{V}}_{1}, \overline{\mathrm{V}}_{2}, \overline{\mathrm{V}}_{6}$ & $\overline{\mathrm{V}}_{3}, \overline{\mathrm{V}}_{4}, \overline{\mathrm{V}}_{5}$ \\
\cline { 3 - 4 } & Torque & $\overline{\mathrm{V}}_{1}, \overline{\mathrm{V}}_{2}, \overline{\mathrm{V}}_{3}$ & $\overline{\mathrm{V}}_{4}, \overline{\mathrm{V}}_{5}, \overline{\mathrm{V}}_{6}$ \\
\hline \multirow{2}{*}{$\boldsymbol{S}_{1}$} & Flux & $\overline{\mathrm{V}}_{1}, \overline{\mathrm{V}}_{2}, \overline{\mathrm{V}}_{6}$ & $\overline{\mathrm{V}}_{3}, \overline{\mathrm{V}}_{4}, \overline{\mathrm{V}}_{5}$ \\
\cline { 2 - 4 } & Torque & $\overline{\mathrm{V}}_{2}, \overline{\mathrm{V}}_{2}, \overline{\mathrm{V}}_{4}$ & $\overline{\mathrm{V}}_{5}, \overline{\mathrm{V}}_{6}, \overline{\mathrm{V}}_{1}$ \\
\hline
\end{tabular}

Switching table of the 12_DTC becomes Tab.3. It is obvious that V1 will produce a large increase in flux and a small increase in torque in sector S12. On the contrary, V2 will increase the torque in large proportion and the flux in a small one. It is reasonable to deduce that the torque error should be divided in the number of intervals that later on will be measured. Therefore, the hysteresis block should have four hysteresis level at is suggested in Fig.7.

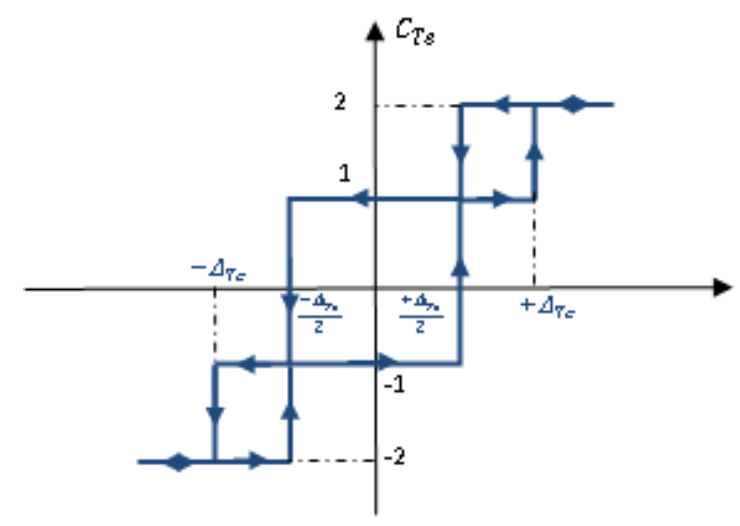

Figure.6: Four levels hysteresis corrector

\section{EXPERIMENTAL RESULTS}

To validate the proposed model, an experiment has been set up [12][13][14]. DSPACE card based on a Texas Instrument TMS320F2812 fixed point DSP is used. As shown in fig 6 , the control is transcribed in MATLAB/Simulink. The real time interface (RTI) is used to build real time code, and to download and execute this code on Dspace hardware .

For the power unit, a voltage source insulated-gate-bipolartransistor-based inverter has been used to feed the induction motor

It is based around the digital signal processor (DSP) TMS320F2812 in assembly by using the Real-Time Workshop (RTW). The Real-Time Workshop converts the Simulink block diagrams to real-time $\mathrm{C}$ code. This software can generate $\mathrm{C}$ code for continuous-time and discrete The eZdspTM F2812 is the link between the DSP based real-time system and the Matlab / Simulink software. This development system eZdspTM F2812 built by Spectrum Digital Inc. company. It is part of the platform C2000TM DSP, and is optimized for applications driving the induction machine. As shown, in Fig.7 (a) there is no big difference between the 6_DTC and 12_DTC in term of distortions but the noises in IM for 12_DTC are clearly decreasing comparing with 6_DTC. Fig 7 (b),(c), (d) and (e) presents respectively currents, stator flux $\Phi s \alpha$ and $\Phi s \beta$, position of flux and sectors for both 6_DTC and 12_DTC, those figures shows that there is no big difference between the performances between the two strategies. Those remarks can be explained by the fact that the number of voltage vectors is not sufficient to have better precision in 12_DTC, for example in spite of using V2 in table 3 which will give us a huge variation, another voltage vector can be used to have a small variation ( a star is putted for the vectors witch don't give us small variation wanted).

\section{CONCLUSION}

In this paper a comparative analysis between different DTC strategies have been presented. This work began by explaining the principle of the 6_DTC and 12_DTC. The proposed models have been implemented using dSPACE board jointed with fixed point DSP, TMS320F2812. Even if the experimental results present no big difference between 6_DTC and 12_DTC, the noises in the IM are clearly decreasing. In fact, 12_DTC associated to a multilevel inverter give the precision wanted by giving a huge number of vectors, the adequate vector is chosen to have a big or small variation and better performances will be obtained. This strategy will be tested by simulation and validated by experimentation in future work. 


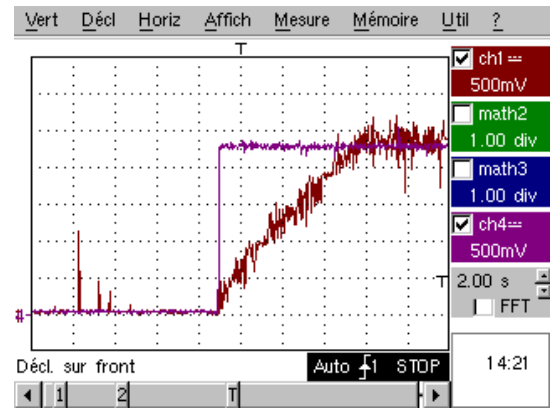

Vert Décl Horiz Affich Mesure Mémoire Uيtil ?

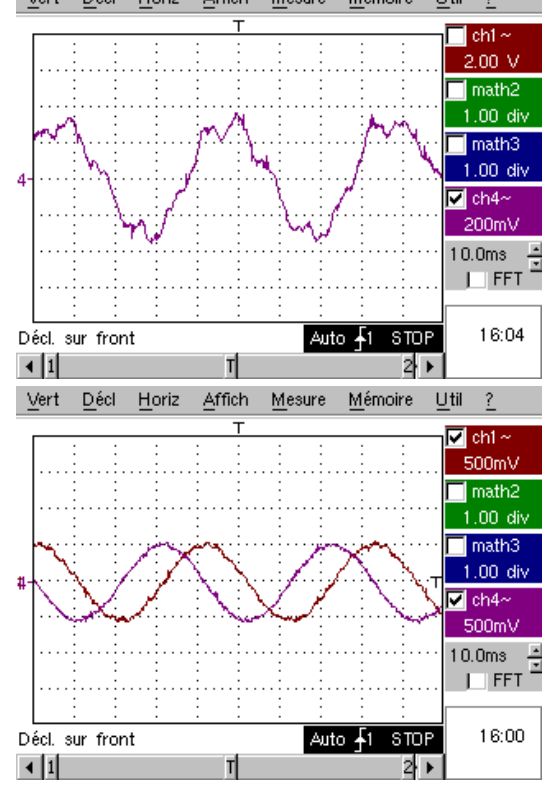

Vert Décl Horiz Affich Mesure Mémoire Uيtil ?

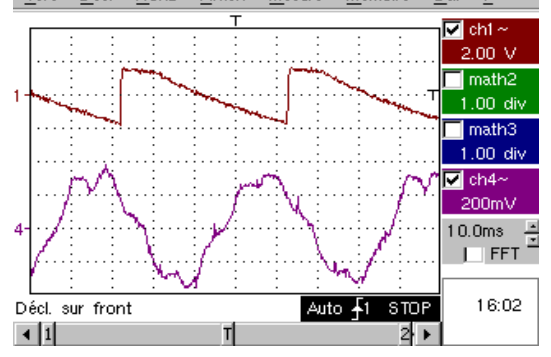

Vert Décl Horiz Affich Mesure Mémoire Util ?

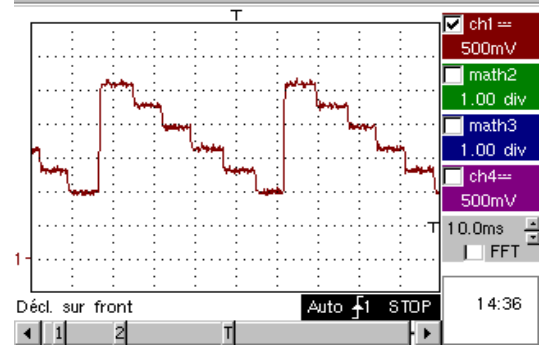

6_DTC (a)

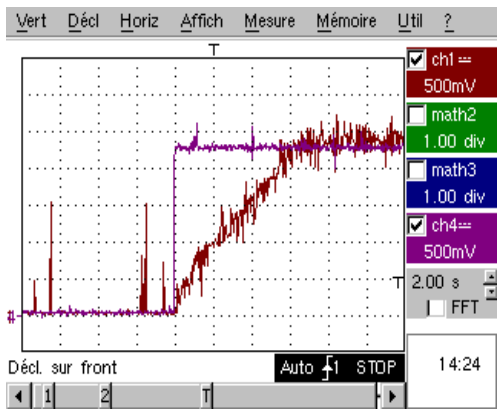

Vert Décl Horiz Affich Mesure Mémoire Util ?

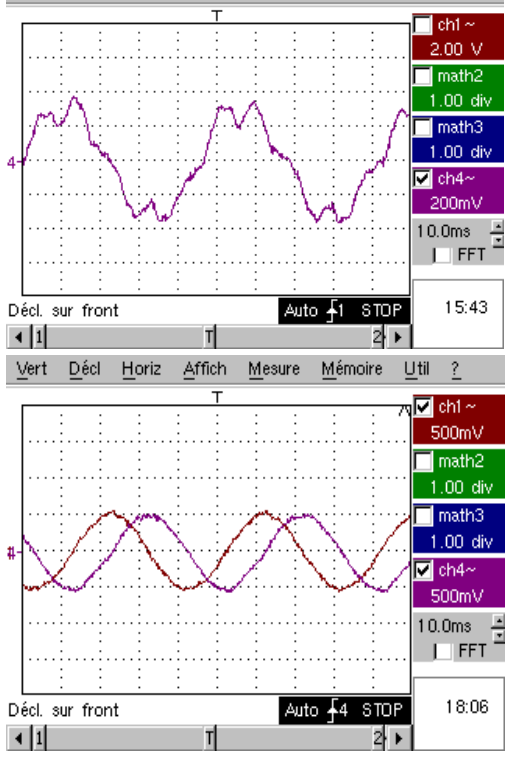

Vert Décl Horiz Affich Mesure Mémoire Uيtil ?

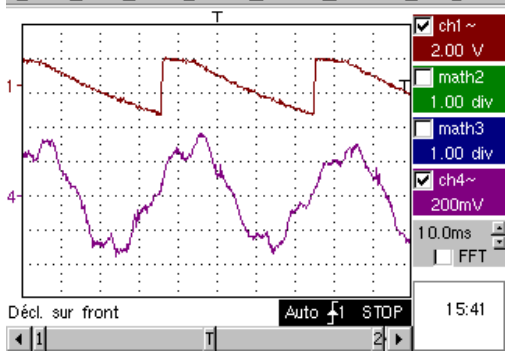

Vert Décl Horiz Affich Mesure Mémoire ultil $\underline{?}$

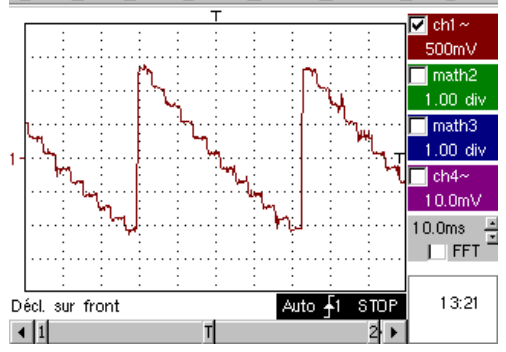

12 DTC

Fig 7: Experimental Comparison between: 6_DTC and 12_DTC in term of (a) torque, (b) current performances, (c) stator flux, (d) position $\theta_{s}$ and (e) sectors 


\section{REFERENCES}

[1] R.Ramya, A.Abhijith, SH. Raju S, M Aditya Bhat and $M$. Thilak "DTC and IFOC feasability analysis on torque control schemes of induction machine," Undergraduate Academic Research Journal (UARJ), ISSN: 2278 - 1129, Volume-2, Issue-3,4,p.4-8,2012

[2] H.Chaikhy, M. Khafallah, A. Saad, and M. Es-saadi "Analysis of the variation effect of induction machine parametersfor vectorial control", Canadian Journal on Electrical and Electronics Engineering Vol. 2, No. 7,p.270-274, July 2011.

[3] R.Toufouti S.Meziane ,H. Benalla“Direct torque control for induction machine using intelligent techniques," Journal of Theoretical and Applied Information Technology,p.35-44,2007.

[4] R.Toufouti S.Meziane ,H. Benalla "Direct torque control strategies for induction machine," Acta Electrotechnica et Informatica No. 1, Vol. 7, p.1-7,2007.

[5] H.Chaikhy, M. Khafallah, A. Saad and K. Chikh "Comparison between FOC and DTC for induction machine" J. Name Stand. Abbrev., in press.between a conventional and an intelligent direct torque control for induction machine",International review on modelling and simulation(IREMOS),Vol.4, No.6,p.28112816,December2011.

[6] B. Metidji, N. Taib, L. Baghli, T. Rekioua, and S. Bacha, "Low-Cost Direct Torque Control Algorithm for Induction Motor Without AC Phase Current Sensors", _IEEE transactions on power electronics, vol. 27, no. 9, september 2012,4132-4139.

[7] H.Chaikhy, M. Khafallah, A. Saad,M.Es-saadi, K. Chikh "Evaluation des performances des commandes vectorielles de la machine à induction", Revue de génie industriel 2011, 6, 23-32.
[8] B. Mokhtari1, A. Ameur, M. F. Benkhoris, L. Mokrani1 and B. Azoui "Experimental DTC of an Induction Motor Applied to Optimize a Tracking System" International Conference on Renewable Energies and Power Quality (ICREPQ'12) Santiago de Compostela (Spain), 28th to 30th March, 2012.

[9] A.Siraj, S. Sao, K. S. R. Anjaneyulu "DTC of Twelve Sector IM Drive Using Four Level Hysteresis Control to Reduce Torque Ripple Comparing with Conventional Control" International Journal of Engineering Research and Applications (IJERA) Vol. 3, Issue 1, JanuaryFebruary 2013, pp.115-120.

[10] T. Prabu, S. Sampathkumar and R. Gunabalan "Advanced Direct Torque Control of Induction motor" Process Automation, Control and Computing (PACC), 2011 International Conference on 20-22 July 2011

[11] B.Bouzidi, A. Yangui, A. guermazi and A. Masmoudi "DTC BASED POSITION CONTROL INDUCTION MOTOR A COMPARISON BETWEEN DIFFERENT STRATEGIES" Systems, Signals and Devices, 2009. SSD '09. 6th International Multi-Conference

[12] X. M. Chen, X. L. Gong, H. X. Zhou, Z. B. Xu, Y. G. $\mathrm{Xu}$, and C. J. Kang "An Economical Rapid Control Prototyping System Design with Matlab/Simulink and TMS320F2812 DSP" Proceeding of the international multiconference of engeneers and computer scientists 2010 Vol II, (IMECS 2010), March 17-19, Hong kong.

[13] A.Safari and S. Mekhilef "Simulation and Hardware Implementation of Incremental Conductance MPPT With Direct Control Method Using Cuk Converter" IEEE TRANSACTIONS ON INDUSTRIAL ELECTRONICS, VOL. 58, NO. 4, APRIL 2011

[14] S.Bayhan, S.Demirbas, I.Garip, "Design and Implementation of DSP-Based ThreePhase PFC" Information, Communication and Automation Technologies (ICAT), 2011 XXIII International Symposium on 27-29 Oct. 2011 